\title{
PENGUASAAN LAHAN, PENDAPATAN, DAN PEMENUHAN DASAR RUMAH TANGGA PETANI DI KABUPATEN KUANTAN SINGINGI
}

\author{
Chezy, Haris, dan Meli \\ Chezywmvermila16@gmail.com
}

\begin{abstract}
ABSTRAK
Tujuan dari penelitian ini adalah untuk mengetahui bagaimana karakteristik petani, tingkat penguasaan lahan, pendapatan, dan pemenuhan kebutuhan dasar rumah tangga. Berdasarkan hasil penelitian didapat umut petani sampel rata-rata 41-59 sebesar 51,81\%, yang mana umur produktif sebanyak 98 orang $(84,08 \%)$ sehingga diketahui bahwa kepala keluarga rumah tangga petani didaerah penelitian tergolong produktif. Penguasaan lahan rumah tangga petani rata-rata memiliki luas lebih dari 2 ha yaitu sebanyak 39 orang $(35,45 \%)$, dengan status kepemilikan lahan adalah hak milik sebesar $94,45 \%$. Dan pendapatan rumah tangga per bulan yaitu Rp. 3.700.000-Rp. 4.700 .000 sebesar 32,72\%.
\end{abstract}

Kata Kunci : Pendapatan, Pemenuhan dasar rumah tangga, petani

\section{PENDAHULUAN}

Lahan bagi petani merupakan faktor produksi yang sangat penting. Lahan merupakan sumber pendapatan untuk kelangsungan hidup. Luas pemilikan dan penguasaan lahan merupakan salah satu faktor utama yang menentukan tingkat penda-patan suatu keluarga atau rumah tangga petani. Oleh karena itu, ketiadaan atau sempitnya pemilikan dan penguasaan lahan merupakan awal terjadinya kemiskinan di pedesaan, seperti yang umumnya terjadi pada kemiskinan di pedesaan Jawa.

Sayogyo (1984), mengemukakan bahwa luas pemilikan tanah adalah salah satu faktor penentu untuk peluang berusaha dan bekerja bagi petani. Singarimbun dan Effendi (1989) menambahkan bahwa tingkat pendapatan usahatani diantaranya dipengaruhi oleh luas tanah dan jenis tanaman. Menurut Tan (1991) tingkat pendapatan usahatani ditentukan oleh luas tanah yang dimiliki, yang mencakup luas tanah pemilikan dan luas tanah usahatani.

Kabupaten Kuantan Singingi mempunyai potensi pertanian yang sangat besar untuk dikembangkan. Daya dukung dan luas lahan yang besar, lebih dari setengah jumlah penduduk bekerja pada sektor pertanian dengan keterampilan dasar yang dimiliki. luas lahan pertanian sawah dari beberapa kecamatan antara lain kuantan mudik, kuantan tengah, benai, kuantan hilir, dan cerenti adalah 16.461 ha. Sedangkan luas lahan pertanian ladang dikecamatan yang sama adalah 4.664 ha (BPS Kuantan Singingi, 2013) dari data tersebut dapat dilihat bahwa petani di Kabupaten Kuantan Singingi lebih banyak disektor tanaman pangan, oleh karena itu 
penulis tertarik untuk melakukan penelitian melihat keterkaitan penguasaan lahan, pendapatan, dan pemenuhan kebutuhan dasar rumah tangga petani di Kabupaten Kuantan Singingi.

Adapun tujuan dari penelitian ini adalah untuk : a) Bagaimana karakteristik petani di Kabupaten Kuantan Singingi b) Bagaimana tingkat penguasaan lahan, pendapatan, dan pemenuhan kebutuhan dasar pada rumah tangga petani di Kabupaten Kuantan Singingi.

\section{METODE PENELITIAN}

\section{Lokasi dan Waktu Penelitian}

Penelitian ini dilakukan dengan metode survei, pada masyarakat petani yang ada di 15 Kecamatan yang ada di Kabupaten Kuantan Singingi. Pemilihan lokasi penelitian ini didasarkan pertimbangan bahwa di Kabupaten Kuantan Singinngi belum pernah dilakukan penelitian tentang penguasaan lahan, pendapatan, dan pemenuhan kebutuhan dasar rumah tangga petani di daerah tersebut. Penelitian ini dilaksanakan selama 10 bulan, mulai dari bulan Desember 2016 sampai bulan Juni 2017, yang meliputi kegiatan penyusunan proposal, pengumpulan data dan pengolahan data serta penulisan hasil penelitian.

\section{Teknik Pengambilan Data}

Data yang dikumpulkan dalam penelitian ini terdiri dari data primer dan data sekunder. Data primer diperoleh dari sampel rumah tangga petani melalui wawancara langsung yang menggunakan daftar quisioner yang telah disusun terlebih dahulu. Data primer tersebut meliputi identitas sampel (umur, jenis kelamin, pendidikan, dan pekerjaa), penguasaan lahan, tingkat pendapatan rumah tangga, pemenuhan kebutuhan dasar (pangan, perumahan, pendidikan dan kesehatan).

Data sekunder meliputi geografi dan topografi, keadaan umum daerah penelitian dan informasi lain yang dianggap perlu untuk menunjang dan melengkapi data penelitian. Data sekunder ini diperoleh dari instansi yang berkaitan dengan penelitian ini.

\section{Teknik Pengambilan Sampel}

Unit analisis penelitian adalah rumah tangga petani, respondennya adalah kepala rumah tangga. Penentu sampel rumah tangga dilakukan secara bertahap (multistage sampling) terdiri dari tiga tahap. Tahap I dipilih 12 Kecamatan sampel, dengan alasan kecamatan ini sebagian besar penduduk hidup dari sektor pertanian. Tahap II dari 12 Kecamatan yang ada dipilih desa sebanyak $50 \%$ dari total desa yang ada di masing-masing kecamatan. 


\section{Analisis Data}

Penguasaan Lahan Rumah Tangga Petani

Penguasaan lahan rumah tangga petani dianalisis secara deskriptif frekuensi.

Pendapata Rumah Tangga Petani

a. Rumus pendapatan rumah tangga, yaitu :

$\mathrm{PRT}=\mathrm{PU}+\mathrm{PNU}$

Ket : $\quad$ PRT $=$ Pendapatan Rumah Tangga $(\mathrm{Rp} / \mathrm{bln})$

PU = Pendapatan Kotor Usahatani (usahatani sawah, sayuran, buah-buahan, buruh tani, dd) (Rp/bln)

PNU = Pendapatan Non Usahatani $(\mathrm{Rp} / \mathrm{bln})$

b. Pendapatan kotor usahatani

pendapatan kotor dapat diperoleh dengan cara mengalikan antara

produksi dengan harga produksi yang berlaku, yang dapat dituliskan dengan cara :

$$
\mathrm{TR}=\mathrm{Py} . \mathrm{Y}
$$

Ket $: \quad T R=$ Pendapatan Kotor $(\mathrm{Rp} /$ luas lahan/musim tanam $)$

Py = Harga produksi $(\mathrm{Rp} / \mathrm{kg})$

$\mathrm{Y}=\mathrm{Jumlah}$ produksi ( $\mathrm{kg} / \mathrm{luas}$ lahan/musim tanam)

\section{HASIL DAN PEMBAHASAN}

\section{Umur}

Umur merupakan yang mempegaruhi seseorang dalam berpikir dan menjalankan aktivitasnya. Umumnya petani yang berusia lebih muda lebih kuat fisiknya dibandingkan dengan petani yang lebih tua.

Berdasarkan hasil penelitian bahwa mayoritas kepala keluarga petani adalah tidak tamat SD yaitu sebanyak 10 orang (9,09\%), tamat SD sebanyak 30 orang (27,27\%), tamat SMP sebanyak 22 orang (20\%) dan tamat SMA bahkan Sarjana sebanyak 48 orang $(43,63 \%)$. Hal ini menunjukkan bahwa tingkat pendidikan kepala rumah tangga petani sudah tinggi. 


\section{Jumlah Tanggungaan Keluarga}

bahwa tanggungan keluarga petani berjumlah 1-7 jiwa dengan rata-rata 4 jiwa, ini berarti jumlah tanggungan keluarga petani tergolong kecil. Besar kecilnya jumlah tanggungan akan mempengaruhi pendapatan petani, semakin kecil jumlah tanggungan keluarga dapat memberikan gambaran hidup lebih sejahtera bagi petani, apabila usahanya berhasil dengan baik.

\section{Pengusaan Lahan}

Berdasarkan hasil penelitian dapat dilihat bahwa rumah tangga petani yang memiliki lahan perkarangan $\leq 0,5$ ha sebanyak 37 orang $(33,63 \%)$, lahan perkarangan dengan luas 0,5 - 1 ha sebanyak 34 orang (30,90\%), lahan perkarangan dengan luas $\geq 2$ ha sebanyak 39 orang $(35,45 \%)$. Sedangkan status kepemilikan untuk lahan perkarangan yaitu sebanyak 104 orang $(94,54 \%)$ berstatus hak milik, yang berstatus milik orang tua/milik adat sebanyak 3,63\%, yang berstatus sewa/bagi hasil sebanyak 1,81\%. Mereka yang mendirikan rumah/tempat tinggal dengan menumpang/ pinjam pakai pada lahan kerabat. Umumnya masih ada hubungan darah, misalnya saudara atau keponaan. Jangka waktunya, ada yang dibatasi dan ada yang tidak. Namun ada pula yang langsung menjadi hak milik, baik melalui pemberian maupun dibeli dengan cara dicicil.

\section{Simpulan}

Dari kegiatan penelitian dapat disimpulkan bahwa tingkat penguasaan lahan untuk lahan pekarangan rata-rata sudah milik sendiri dengan jumlah 14,75\% dan penguasaan lahan pertanian $13,16 \%$. Rata-rata penggunaan lahan kebun I 7.808 penguasaan lahan dan Kebun II 974. Struktur Pendapatan Rumah tangga petani pertanian 8.600.000.

\section{Saran}

Berdasarkan hasil pengamatan dilapangan, wawancara dan analisis data, saran untuk pemberdayaan pekarangan di Kabupaten Kuantan Singingi.

1. Diperlukan bantuan untuk mendapatkan input usaha tani terjangkau dari segi harga maupun tempat pembelian

2. Diperlukan adanya penguatan kelompok dan pendampingan dalam kegiatan pemberdayakan pekarangan. 


\section{DAFTAR PUSTAKA}

Depertement Pertanian Republik Indonesia. 2011. Pedoman Umum Penyusunan rogram Pengembangan Konsumsi Pangan. http://www.deptan.go.id/pesantren/bkp/PKP/pedoman_umum.htm (24 Mei 2018).

Erizal, dkk. 2002. Reforma Agraria dan Masa Depan Pertanian. Jurnal Litbang Pertanian, 21 (4) 133-139. IPB Press. Bogor.

Goble F.G. 2000. Mazhab Ketiga Psikologi Humanistik Abraham Maslow (terjemahan dari buku The third Force, The Psychology of Abraham Maslow). Kanisius. Yogyakarta.

Gatot, I. 2006. Pengelolaan Sumberdaya Lahan \& Air : Strategi Pendekatan dan Pendaya gunaannya. Papas Sinar Sinanti. Jakarta.

Hanani. 2009. Monitoring dan Evaluasi Ketahanan Pangan http://lecture.ub.ac.id/nuhfil/files/2009/03/7pemetaan-rawan-pangan-7.pdf( 15 Maret 2018).

Sajogyo. 1984. Memahami dan menanggulangi Kemiskinan di Indonesia. Jakarta: Grsindo.

Simatupang, P. 1995. Industrialilasi Pertanian Sebagai Strategi Agribisnis dan Pembangunan Pertanian dalam Era Globalisasi. Orasi Pengukuhan sebagai APU Pusat Penelitian Sosial Ekonomi Pertanian, Bogor. 